\title{
Epidemiology and management of gout in Taiwan: a nationwide population study
}

\author{
Chang-Fu Kuo ${ }^{1,2}$, Matthew J Grainge ${ }^{3}$, Lai-Chu See ${ }^{4,5}$, Kuang-Hui Yu², Shue-Fen Luo², Weiya Zhang ${ }^{1 *}$ \\ and Michael Doherty ${ }^{1}$
}

\begin{abstract}
Introduction: Gout is the most common inflammatory arthritis worldwide and is the only type of chronic arthritis that potentially can be 'cured'. However, data on gout incidence, prevalence and management, assessed at multiple time points in the same population, are sparse, particularly in Asian populations. The aim of this study was to describe trends in the epidemiology of gout in the general population of Taiwan.

Methods: The National Health Insurance Research Database was used to identify patients with gout and to estimate the prevalence and incidence of gout for each calendar year from 2005 to 2010. The pattern of gout management was also examined.

Results: Of 23,371,362 beneficiaries in 2010, there were 1,458,569 prevalent and 56,595 incident cases of gout, giving a prevalence of $6.24 \%$ (95\% confidence interval $(\mathrm{Cl}), 6.23 \%$ to $6.25 \%$ ) and an incidence of 2.74 (95\% Cl, 2.72 to 2.76 ) per 1,000 person-years. The annual percentage change (APC) of the standardised prevalence was $-0.7 \%$ ( $95 \% \mathrm{Cl},-1.7 \%$ to $0.3 \% ; P=0.14$ ), suggesting that the prevalence of gout was essentially the same throughout the study period. However, The APC of incidence was -13.4 ( $95 \% \mathrm{Cl},-16.1$ to -10.6$)$ between 2005 and 2007 and -2.1 ( $95 \% \mathrm{Cl},-10.4$ to 7.1$)$ between 2007 and 2010. Regions with the highest prevalence and incidence were eastern coastal counties and offshore islets, where indigenous people are clustered. Among prevalent gout cases in 2010, only $22.93 \%$ (95\% Cl, 22.87\% to $23.00 \%)$ were prescribed urate-lowering treatment (ULT), which remained unchanged between 2005 and 2010 at an APC of $0.0(95 \% \mathrm{Cl},-3.8$ to 4.0). Uricosuric agents were more commonly prescribed than xanthine oxidase inhibitors in Taiwan.
\end{abstract}

Conclusions: In Taiwan, 1 in 16 people have gout. Whereas the incidence has decreased recently, the prevalence remains unchanged. Management of gout in Taiwan is poor, with only one in five affected people being treated with ULT.

\section{Introduction}

Gout is the most common inflammatory arthritis and constitutes a rising disease burden worldwide [1]. Gout is defined by the presence of monosodium urate crystals which deposit as a consequence of chronic elevation of serum urate above the saturation point for urate crystal formation. The main accepted clinical consequences of gout are recurrent episodes of acute painful arthritis (gout 'attacks'), irreversible peripheral joint damage, subcutaneous tophi, urate nephropathy and urolithiasis [2].

\footnotetext{
* Correspondence: weiya.zhang@nottingham.ac.uk

'Division of Rheumatology, Orthopaedics and Dermatology, School of

Medicine, University of Nottingham, Academic Rheumatology, Clinical Sciences Building, Nottingham City Hospital, Hucknall Road, Nottingham NG5 1PB, UK

Full list of author information is available at the end of the article
}

Reducing and maintaining serum urate levels below the saturation point can prevent further crystal formation and promote dissolution of existing urate crystals, thereby eliminating the pathogenic agents and leading to 'cure'. However, despite its high prevalence and relatively well-understood pathogenesis, as well as the existence of definitive urate-lowering therapy (ULT), gout is largely ignored by physicians in primary care [3], who very often treated it as an acute illness rather than as a chronic disease with major adverse consequences [4-6].

The prevalence and incidence of gout have a distinct geographical and racial distribution [7]. In a recent gout study in the United Kingdom, researchers found a prevalence of $2.49 \%$ and an incidence of 1.77 per 1,000 person-years in 2012, with both figures being higher than earlier estimates [8]. In the United States, the 
National Health and Nutrition Examination Survey team also found a high prevalence of gout, which was 3.9\% between 2007 and 2008 [9]. Contemporary data on gout epidemiology are relatively scant in other countries. Taiwan is one of the countries with the highest prevalence of gout worldwide [10-17]. In a recent nationwide survey (the Nutrition and Health Survey in Taiwan), researchers reported gout prevalence data of $8.2 \%$ in men and $2.3 \%$ in women in the period from 2005 to 2008 [17], which is close to the estimates for 2004 based on information derived from the National Health Insurance Research Database (NHIRD) [18]. In particular, Taiwanese aborigines have a very high prevalence of gout $[11,12]$, which is shared with their genetically related Polynesian cousins [19], the Māori and indigenous Oceania/Pacific Islander populations [20]. The incidence of gout has not been estimated in Taiwan previously, and the current standard of care in Taiwan as reflected by the use of ULT has not been examined to date.

Therefore, we undertook this study to examine the prevalence and incidence of gout and the patterns of gout management between 2005 and 2010 using the NHIRD, which contains comprehensive information on diagnoses, prescriptions and hospitalisations of essentially the entire population in Taiwan.

\section{Methods}

The study was approved by the institutional review board of Chang Gung Memorial Hospital (approval number 101-2178C). All data in this study were anonymised; therefore, the need for patient consent was waived.

\section{Source of data and study population}

In this study, we used data from the NHIRD, which contains registration files and original claims data from approximately 28.75 million (living and deceased) beneficiaries registered in the database between March 1995 and the end of 2010. We requested from the National Health Research Institute (the data holder of NHIRD) a tailormade dataset containing data of all patients with a diagnosis of gout. Denominator data were based on the Registry of Beneficiaries, a part of NHIRD with records of the demographics, insurance status, residence and socioeconomic data of all beneficiaries. However, ethnicity data were not available. Our study comprised all beneficiaries registered continuously between 1 January 2005 and 31 December 2010.

\section{Case definition of gout}

The primary case definition of gout was having a physicianrecorded primary diagnosis of gout (International Classification of Diseases, Ninth Revision, code 274.x) at either an outpatient or emergency visit. By searching the entire NHIRD, we obtained data on all patients with gout recorded between 1995 and 2010.

\section{Estimation of prevalence and incidence}

Prevalent cases of gout were defined as individuals who had at least one record of a primary diagnosis of gout within the 10-year period before 1 July of each calendar year. The denominator for prevalence estimation (the eligible population) for each calendar year included all individuals registered on 1 July of each calendar year. Prevalence was calculated using the number of prevalent cases of gout divided by the eligible population in the specified calendar year.

Incident cases of gout defined as those patients who had no evidence of gout or use of ULT within the 10year period prior to 1 January of each calendar year but who developed gout during that year. We chose to fix the observational period to 10 years for two reasons: (1) The NHIRD does not have data going back further than 10 years for beneficiaries registered in 2005, and (2) the majority of prevalent gout cases can be identified within a 10-year observation period, according to a previous cohort study [21]. To be eligible to be considered as incident gout cases, beneficiaries had to have at least a 1-year registration period prior to 1 January of each calendar year. For the incidence of gout, we constructed at-risk cohorts for each calendar year, comprising all individuals registered during the given calendar year who had no history of a gout diagnosis before 1 January of that year. Incidence was calculated using the number of incident gout cases during a calendar year as the numerator and the total person-years in an at-risk population accumulated during that same year as the denominator.

Prevalence and incidence were calculated for 21 cities and/or counties in Taiwan (termed regions hereinafter): Taipei city, Taipei county, Keelung city, Taoyuan county, Hsinchu city and county, Yilan county, Miaoli county, Taichung city, Taichung county, Changhua county, Yunlin county, Nantou county, Chiayi city and county, Tainan city, Tainan county, Kaohsiung city, Kaohsiung county, Pingtung county, Hualien county, Taitung county and offshore islets (Penghu, Kinmen and Lienchiang counties). To remove the effect of different age and sex structures in these regions, we standardised prevalence and incidence with respect to the overall population structure of 2010 . We used choropleth maps to represent geographic variations in gout incidence and prevalence between different regions of Taiwan.

\section{Pattern of medication use}

For each calendar year from 2005 to 2010, we ascertained the proportion of prevalent gout cases in which the patient received ULT (allopurinol, benzbromarone, probenecid or sulfinpyrazone). 
Trends of prevalence, incidence and management of gout To determine the trends in prevalence, incidence and management of gout, we calculated age- and sexstandardised prevalence, incidence of gout and pattern of ULT prescribing in each calendar year from 2005 to 2010 with the population structure in 2010 used as the reference.

\section{Statistical analysis}

The 95\% confidence intervals (CIs) for prevalence and incidence were derived on the basis of the assumption of a Poisson distribution for the observed number of prevalent and incident cases. We used the Joinpoint Regression Program (version 4.0.4; National Cancer Institute, Bethesda, MD, USA) to estimate trends in the prevalence and incidence of gout. We used the Bayesian information criterion in the program to generate different numbers of "join points' in time when the linear trend of prevalence and incidence of gout changed significantly and to determine the best-fit data series [22]. A maximum of two join points was used to determine statistical significance for trend. Annual percentage changes (APCs) for each segment were calculated. The significance level was set at 0.05. All statistical analyses were performed using SAS statistical software, version 9.3 (SAS Institute, Cary, NC, USA).

\section{Results}

\section{Prevalence and incidence of gout in $\mathbf{2 0 1 0}$}

Of 23,371,362 beneficiaries (men: 49.56\%) included within the NHIRD in 2010, 1,458,569 prevalent cases of gout were identified, giving a prevalence of $6.24 \%$ (95\% CI, $6.23 \%$ to $6.25 \%$ ). Men had a significantly higher prevalence of gout $(9.34 \%$; $95 \%$ CI, $9.32 \%$ to $9.36 \%$ ) than women (3.20\%; $95 \% \mathrm{CI}, 3.19 \%$ to $3.21 \%)$. Overall, the prevalence of gout was 2.9-fold higher in men than in women. This sex difference was observed in all age groups, with a male-to-female ratio of 4.5 in individuals younger than 20 years, peaking at 7.3 in those ages 30 to 34 years and then decreasing thereafter. Gout was rare in people younger than 20 years of age, and it increased with age, reaching a peak in the 80- to 84-year-old age band (Figure 1a).

There were a total $20,677,590$ person-years of followup in 2010, during which 56,595 incident cases of gout were identified (overall incidence, 2.74 (95\% CI, 2.72 to 2.76) per 1,000 person-years). Men had a higher incidence of gout (4.10 (95\% CI, 4.06 to 4.14$)$ per 1,000 person-years) than women (1.49 (95\% CI, 1.47 to 1.52 ) per 1,000 person-years). As shown in Figure 1b, the incidence of gout in men was low in those younger than 20 years of age but increased rapidly until ages 35 to 39 years. After a relative plateau in gout incidence during middle age, gout incidence again showed a sharp increase, reaching a peak between ages 70 and 74 years. In
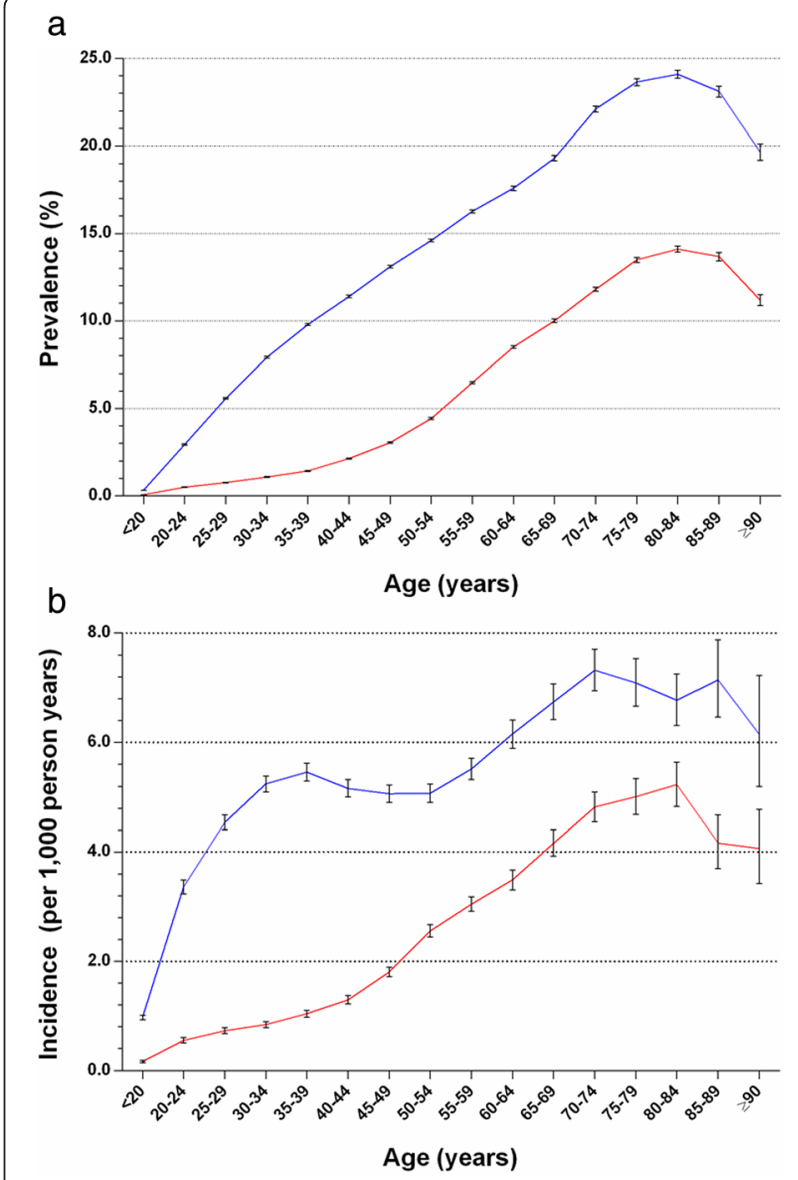

Figure 1 Age-specific prevalence (a) and incidence (b) of gout in Taiwan in 2010. Blue: men; red: women.

women, the incidence of gout remained low before the age of 40 , but thereafter it started to increase rapidly, reaching a peak incidence at the age band of 80 to 84 years. The greatest male-to-female incidence ratio (6.2) was observed in those ages 30 to 34 years, and thereafter the difference between men and women diminished.

\section{Prevalence and incidence of gout between 2005 and 2010}

Table 1 shows the temporal trends in prevalence and incidence of gout from 2005 to 2010. In general, the standardised estimates were slightly higher than the crude ones, accounting for the fact that the population was aging over time (refer to Additional file 1: Figure S1 for population pyramids of Taiwan in 2005 and Additional file 2: Figure S2 for 2010). The crude prevalence of gout increased $5.6 \%$, but the standardised prevalence fluctuated and decreased by $3.1 \%$ over the study period. The annual percentage change of the standardised prevalence was -0.7 ( $95 \% \mathrm{CI},-1.7$ to 0.3$)$, but this was not statistically significant $(P=0.14)$, suggesting that the prevalence of gout was essentially the same throughout the 
Table 1 Crude and standardised prevalence and incidence of gout from 2005 to 2010

\begin{tabular}{|c|c|c|c|c|c|c|}
\hline \multirow[t]{2}{*}{ Year } & \multicolumn{3}{|c|}{ Prevalence (\%) } & \multicolumn{3}{|c|}{ Incidence (per 1,000 person-years) } \\
\hline & $N$ & Crude & Standardised & Person-years & Crude & Standardised \\
\hline \multicolumn{7}{|c|}{ Overall } \\
\hline 2005 & $23,000,521$ & 5.91 (5.90 to 5.92) & 6.44 (6.43 to 6.45$)$ & $20,543,857$ & 3.81 (3.78 to 3.84 ) & 3.93 (3.90 to 3.96$)$ \\
\hline 2006 & $23,127,946$ & $6.14(6.13$ to 6.15$)$ & 6.58 (6.57 to 6.59$)$ & $20,559,914$ & 3.21 (3.19 to 3.24$)$ & 3.29 (3.27 to 3.31$)$ \\
\hline 2007 & $23,221,905$ & $6.22(6.21$ to 6.23$)$ & 6.55 (6.54 to 6.56$)$ & $20,602,277$ & 2.89 (2.86 to 2.91$)$ & 2.93 (2.91 to 2.96$)$ \\
\hline 2008 & $23,315,001$ & 6.27 (6.26 to 6.28) & 6.49 (6.48 to 6.50$)$ & $20,645,964$ & 2.89 (2.87 to 2.92$)$ & 2.91 (2.88 to 2.93 ) \\
\hline 2009 & $23,344,259$ & $6.30(6.29$ to 6.31$)$ & 6.41 (6.40 to 6.42$)$ & $20,666,404$ & 2.80 (2.78 to 2.82$)$ & 2.79 (2.76 to 2.81$)$ \\
\hline 2010 & $23,371,362$ & $6.24(6.23$ to 6.25$)$ & $6.24(6.23$ to 6.25$)$ & $20,677,590$ & $2.74(2.72$ to 2.76$)$ & $2.74(2.72$ to 2.76$)$ \\
\hline \multicolumn{7}{|l|}{ Men } \\
\hline 2005 & $11,550,180$ & 8.35 (8.33 to 8.36$)$ & 9.01 (8.99 to 9.02 ) & $10,048,241$ & 5.55 (5.47 to 5.56$)$ & 5.64 (5.59 to 5.68$)$ \\
\hline 2006 & $11,579,907$ & 8.74 (8.72 to 8.76$)$ & 9.28 (9.27 to 9.30 ) & $10,001,584$ & 4.68 (4.64 to 4.72 ) & 4.76 (4.71 to 4.80 ) \\
\hline 2007 & $11,598,597$ & 8.98 (8.96 to 8.99) & 9.40 (9.38 to 9.41$)$ & $9,969,808$ & 4.26 (4.22 to 4.30$)$ & 4.30 (4.26 to 4.34$)$ \\
\hline 2008 & $11,615,445$ & 9.16 (9.14 to 9.18) & 9.45 (9.43 to 9.47 ) & $9,944,293$ & 4.26 (4.22 to 4.30$)$ & 4.26 (4.22 to 4.30$)$ \\
\hline 2009 & $11,597,439$ & 9.32 (9.30 to 9.34$)$ & 9.47 (9.45 to 9.48$)$ & $9,907,190$ & 4.16 (4.12 to 4.20$)$ & 4.13 (4.09 to 4.17 ) \\
\hline 2010 & $11,583,208$ & 9.34 (9.32 to 9.36) & 9.34 (9.32 to 9.36 ) & $9,868,937$ & 4.10 (4.06 to 4.14$)$ & 4.10 (4.06 to 4.14$)$ \\
\hline \multicolumn{7}{|c|}{ Women } \\
\hline 2005 & $11,450,341$ & 3.46 (3.45 to 3.47 ) & 3.92 (3.91 to 3.93 ) & $10,495,616$ & 2.18 (2.15 to 2.20$)$ & 2.37 (2.34 to 2.40 ) \\
\hline 2006 & $11,548,039$ & 3.54 (3.53 to 3.55 ) & 3.92 (3.91 to 3.93 ) & $10,558,330$ & 1.82 (1.79 to 1.84$)$ & 1.95 (1.92 to 1.97$)$ \\
\hline 2007 & $11,623,308$ & 3.48 (3.47 to 3.49 ) & 3.76 (3.75 to 3.77 ) & $10,632,469$ & 1.60 (1.57 to 1.62 ) & $1.68(1.66$ to 1.71$)$ \\
\hline 2008 & $11,699,556$ & 3.40 (3.39 to 3.41$)$ & 3.59 (3.57 to 3.60$)$ & $10,701,671$ & 1.62 (1.60 to 1.65$)$ & 1.67 (1.65 to 1.70$)$ \\
\hline 2009 & $11,746,820$ & 3.31 (3.30 to 3.32) & 3.41 (3.40 to 3.42 ) & $10,759,214$ & 1.55 (1.52 to 1.57$)$ & 1.56 (1.54 to 1.58$)$ \\
\hline 2010 & $11,788,157$ & 3.20 (3.19 to 3.21$)$ & 3.20 (3.19 to 3.21$)$ & $10,808,653$ & 1.49 (1.47 to 1.52$)$ & 1.49 (1.47 to 1.52 \\
\hline
\end{tabular}

study period after adjusting for age. There was no significant join point for the trend in gout prevalence. As Figure $2 \mathrm{a}$ shows, the temporal trend in prevalence among men and women was not parallel $(P<0.001)$. The annual percentage change was 1.0 (95\% CI, 0.1 to $1.9)$ in men and -4.0 (95\% CI, -5.4 to -2.7$)$ in women. The male-to-female ratio increased slightly from 2.3 in 2005 to 2.9 in 2010.

In contrast, both the crude and standardised incidences of gout declined over time during this period, with the standardised incidence reducing by $30.3 \%$ (Figure 2b). On average, the annual percentage change of gout incidence was -6.7 (95\% CI, -10.7 to -2.6$)$, and there was one join point (in 2007). The annual percentage changes of gout incidence were -13.4 (95\% CI, -16.1 to -10.6) during the period between 2005 and 2007 and -2.1 (95\% CI, -10.4 to 7.1 ) during the period from 2007 to 2010. Figure $2 \mathrm{~b}$ shows the trend in gout incidence for men and women $(P=0.02)$, with an annual percentage change of -8.5 (95\% CI, -12.6 to -4.3$)$ in men and -5.9 (95\% CI, -9.9 to -1.8 ) in women. However, in both men and women, the trends of gout incidence in the period from 2007 to 2010 were essentially flat, with annual percentage changes (95\% CIs) of $-3.8(-12.9$ to 6.3$)$ for men and -1.3 (-9.6 to 7.7$)$ for women. The male-to-female ratio of incidence slightly increased from 2.4 in 2005 to 2.7 in 2010.

\section{Geographic variation in 2010}

Neither the prevalence nor the incidence of gout was uniform throughout Taiwan. As shown in Figure 3, the standardised prevalence $(95 \% \mathrm{CI})$ of gout was highest in the eastern coastal counties and offshore islets. The regions with the lowest prevalence of gout were mostly in the urban areas (Taipei city, Taichung city, Tainan city and Kaohsiung city). The regional pattern of gout incidence resembled that of gout prevalence, with a higher incidence in the eastern coastal counties and offshore islets and a lower incidence in the urban areas.

\section{Management of gout between 2005 and 2010}

Of the $1,458,569$ prevalent gout cases in 2010, approximately one-third of patients had consulted for gout or had been treated with ULT $(n=515,004 ; 35.31 \%(95 \%$ CI, $35.23 \%$ to $35.39 \%)$ ). However, only one in five prevalent gout cases in 2010 involved patients who were treated with ULT ( $n=334,518 ; 22.93 \%$ (95\% CI, $22.87 \%$ to $23.00 \%)$ ). Among patients who received ULT treatment, $60.08 \%$ (95\% CI, 59.91\% to $60.25 \%$ ) received uricosuric agents alone, $28.54 \%$ (95\% CI, $28.39 \%$ to $28.69 \%$ ) 


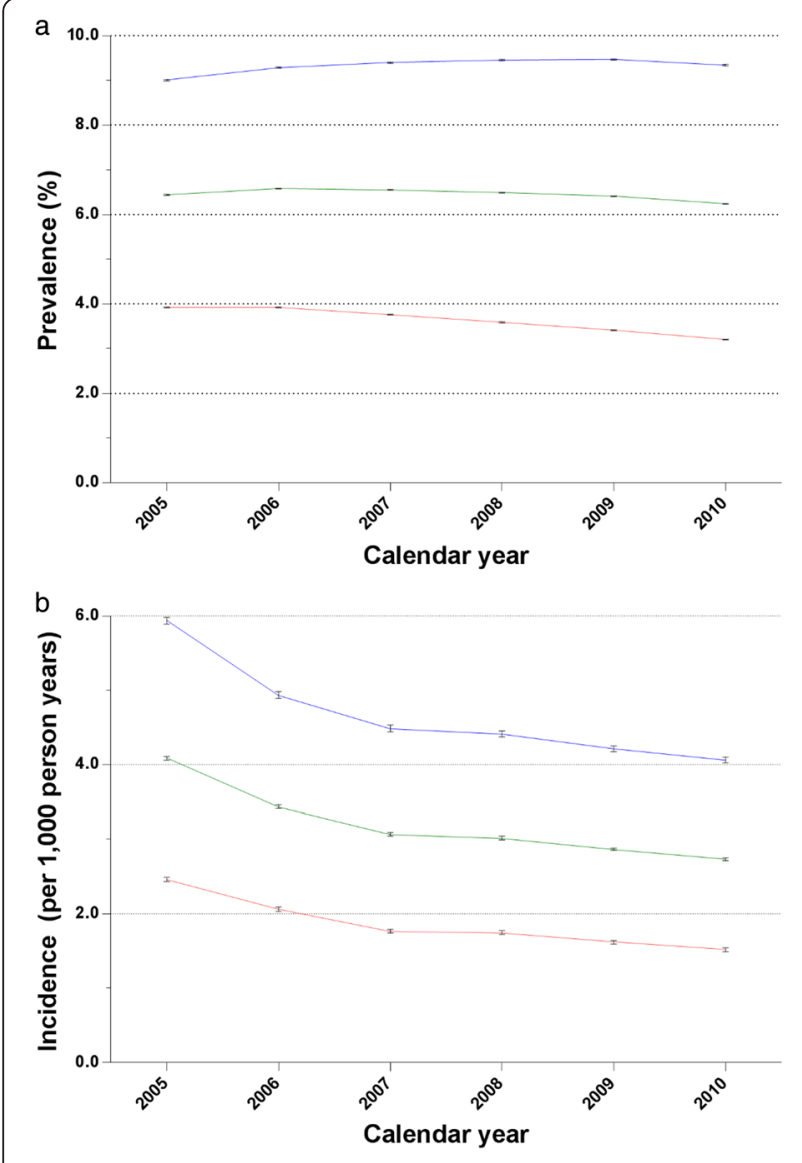

Figure 2 Differences by sex in the trends of standardised prevalence (a) and incidence (b) of gout in Taiwan between 2005 and 2010. Blue: men; red: women; green: overall).

received a xanthine oxidase inhibitor and $11.38 \%(95 \%$ CI, $11.27 \%$ to $11.49 \%$ ) received both. As shown in Figure $4 \mathrm{a}$, the proportion of prevalent cases in which patients received consultations for gout or were treated by ULT remained low during the whole study period, with an APC of -0.9 (95\% CI, -6.2 to 4.7). Similarly, the proportion of patients who received ULT did not change during this time, with an APC of 0.0 (-3.8 to 4.0).

\section{Discussion}

In this nationwide population study covering the entire 23 million population of Taiwan, about 1 in 16 residents of Taiwan was affected by gout during the study period. Whereas the incidence decreased, the prevalence of gout was fairly stable over the period between 2005 and 2010 . Despite the small size of Taiwan (only $36,193 \mathrm{~km}^{2}$ ), both the prevalence and incidence of gout showed marked geographical variation. This regional variation in gout generally coincided with the distribution of aboriginal people in Taiwan, who primarily reside in eastern counties and rural areas. Although gout is one of the most common chronic diseases in Taiwan, it seems that the management of gout remains poor, with only one-third of people with gout receiving medical attention and only one-fifth being given ULT. Unfortunately, this suboptimal care did not change over the study period, despite the publication of national and international guidelines on gout management during this time.

The trends of gout prevalence in Taiwan have not been robustly examined until now. In general, surveys conducted in the 1990s [10-14] reported a lower prevalence of gout than those conducted in the 2000s [15-18]. The National Nutrition and Health Survey in Taiwan undertaken in the period between 1993 and 1996 found the prevalence of gout to be $4.74 \%$ in men and $2.19 \%$ in women [14], whereas the same survey conducted between 2005 and 2008 found the prevalence of gout to be $8.21 \%$ in men and $2.33 \%$ in women [17]. However, these estimates were based on patients' self-reported gout and were not standardised for age structure, despite use of stratified probability sampling considering age, sex, geographical region and ethnicity in the respective study periods. In our present study, we found that the crude prevalence of gout increased over time but that the ageand sex-standardised prevalence remained stable between 2005 and 2010. There were different trends in gout prevalence in men and women, with the prevalence in men reaching a plateau after 2007 , whereas the prevalence in women continued to decrease throughout the study period.

Several caveats should be considered before drawing conclusion about trends in gout prevalence in Taiwan. First, most previous studies were based on patients' selfreported gout [10-17], which has inherent bias. For example, in the Atherosclerosis Risk in Communities (ARIC) cohorts [23], only $73 \%$ of patients with gout diagnosed by this means in 2000 also reported gout in the follow-up questionnaire in 2003, and only $65 \%$ reported gout in the 2003 and 2007 questionnaires. In a Dutch study, researchers found that only $64 \%$ of patients with gout self-reported it after just 6 months of followup [24]. Furthermore, an earlier study found that only $44 \%$ of self-reported gout cases had this confirmed by medical chart review and physician interview [25]. These studies confirm significant bias connected to selfreported gout. In our previous study conducted in 2004 [18], in which we also used the NHIRD as the primary data source, we found a much lower prevalence of gout (4.62\%) than the estimate in 2005 in this study (5.91\%). We consider that this disparity is primarily a result of the different lengths of observation (5 years in the previous study and 10 years in the present study) and therefore different degrees of identification of clinically silent patients. It is difficult to determine to what extent a shorter observation period might lead to underestimation of prevalence. In one case series, reported in 1961, 

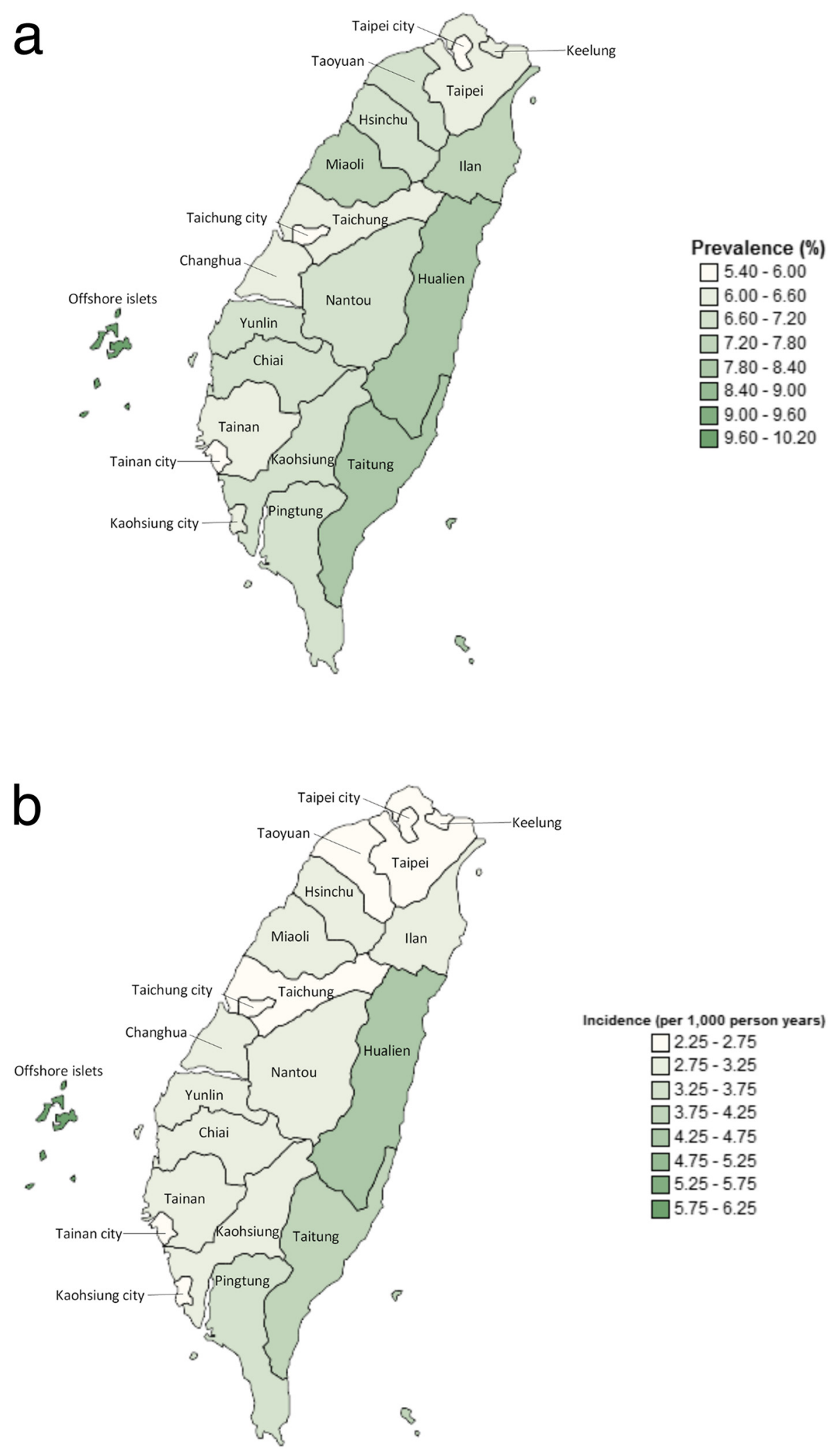

Figure 3 Geographic variation in the prevalence (a) and incidence (b) of gout in Taiwan in 2010. 


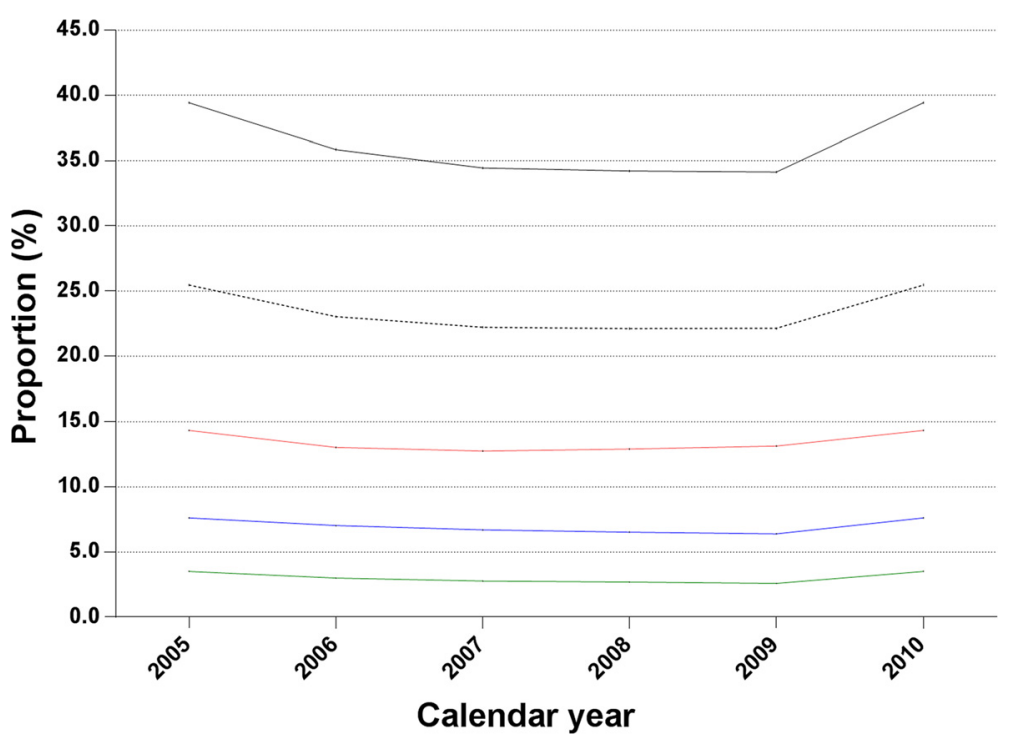

Figure 4 Secular trends of treatment of gout in Taiwan. Proportion of prevalent gout cases in which patients received consultations for gout or underwent urate-lowering treatment (black line), only received urate-lowering treatment (black dotted line), received uricosuric agents (red line), received a xanthine oxidase inhibitor (blue line) or received both (green line).

the length of intercritical periods was less than 1 year in $62 \%$, from 1 to 5 years in 27\%, from 6 to 10 years in $4 \%$ and over 10 years in $7 \%$ of 614 patients [21]. Therefore, the gout prevalence in 2004 in our previous study could have been underestimated, because the length of the observation period was too short.

The incidence of gout has not been estimated previously in Taiwan, and incidence data in other countries also are relatively scarce. The largest population-based study was conducted in Rochester, MN, USA, In that study, researchers estimated annual incidences of 0.45 per 1,000 person-years and 0.62 per 1,000 person-years during the periods from 1977 to 1978 and 1995 to 1996, respectively [26]. In the Framingham study in the United States, researchers estimated an average annual incidence of 1.6 and 0.2 per 1,000 person-years for men and women, respectively, during the period between 1948 and 1980 [27], Those data are similar to the data reported for men in the John Hopkins Precursors Study, in which researchers found an incidence of 1.73 per 1,000 person-years in 1,216 male medical students over a median of 29 years [28]. Using data from the UK Second and Third National Studies of Morbidity in General Practice, the overall gout incidence was estimated to be 1.4 per 1,000 person-years in 1981 [29]. More recently, Mikuls et al. used the General Practice Research Database (GPRD) and estimated the UK all-age incidence of gout to be 1.31 cases per 1,000 person-years in 1999 [30]. Our recent estimate of UK gout incidence in 2012, using the same database, was 1.77 per 1,000 person-years [8]. However, all these estimates relate to Caucasians, and gout incidence has rarely been estimated in people of other ethnicities. Hochberg et al. reported that the incidence of gout in the period between 1958 and 1965 in African Americans was 3.11 per 1,000 person-years, which was 1.7-fold higher than that of Caucasians [28]. Similarly, the ARIC study researchers reported that the gout incidences in the period between 1987 and 2012 were 1.55 and 0.94 per 1,000 person-years for African American men and Caucasian American men, respectively [31]. To the best of our knowledge, our study is the first in which gout incidence has been reported in an Asian population. The incidence of gout in Taiwan was much higher than in other countries, suggesting significant racial and geographic variation in the aetiology of gout.

The age-specific incidence of gout is rarely reported. Data from the UK Second and Third National Studies of Morbidity in General Practice and the Framingham study, each undertaken in the 1980s, revealed that gout incidence peaked around the 50s age band [27,29]. More recently, Mikuls et al., who used the GPRD, found that gout incidence peaked later, between the ages of 65 and 84 years [30]. In our estimates in 2012, for which we used the same UK database, we also found a similar, later age of peak incidence [8]. In Taiwan, we have found that gout incidence peaks later, between the ages of 70 and 85 years. However, there was a significant difference in age-specific incidence between men and women. In men, we found a nonlinear distribution of age-specific incidence of gout, wherein a marked increase in gout incidence occurred in the two age bands of 20 to 39 and 50 to 69 years of age. In contrast, in women, age-specific incidence demonstrated a near-linear increase in the incidence of gout with age up to the peak incidence 
between ages 80 and 84 years. This appears unique compared with previous studies on age-specific incidence $[27,29,30]$ in which investigators report a linear increase in the incidence of gout with age up to the peak and then a levelling off or slight decrease in both men and women thereafter. Our findings echo those of a previous study by $\mathrm{Yu}$ et al. which indicated that the onset of gout occurs earlier in Taiwanese [32] than in Caucasians [33] and Japanese [34]. The very high prevalence and incidence in Taiwan compared to that in China [35] and Japan [36], and the unique age-specific distribution of incidence, may partly reflect the composition of Taiwanese residents, a mixture of Han Chinese and indigenous people, who are known to be very prone to gout $[11,37]$ and who are genetically related to Polynesians and Oceania/Pacific Islander populations [19]. This population stratification was also demonstrated by the regional variation in gout prevalence and incidence because the areas with the highest prevalence and incidence were those with the highest density of indigenous people with the highest genetic risk. However, genetic factors account for just one-third of phenotypic variation of gout in men and only one-fifth in women [18], so environmental factors could also contribute to the variable geographical distribution of gout in Taiwan. Further studies are required to address this issue.

In our present study, we found a trend of decreasing incidence, but generally a flattening of prevalence, during the study period. Several explanations may account for this finding. Firstly, relationships between incidence and prevalence are complex and involve other factors, such as disease duration and mortality [38]. In addition, the static relationship between prevalence and incidence is primarily based on a stable population with constant parameters [39]. Our study population was not stationary, and both prevalence and incidence were changing. Therefore, the change in incidence probably needs several years to translate to changes in prevalence. Secondly, the study period was probably too short, and longer observation would be required to measure long-term trends of prevalence and incidence accurately. Thirdly, NHI started in March 1995 in Taiwan, so the observation period in 2005 was 3 months short of 10 years of observation in estimates of other calendar years. This could have led to overestimation of incidence in 2005, the year showing the highest incidence of gout in the study period. The results of our study demonstrate that both prevalence and incidence were stationary after 2007, a period that is less liable to bias due to differential observation time. These results collectively show that gout prevalence and incidence were not increasing in the years studied, in contrast to the global trends. Further study is required to confirm our findings.

Regardless of the high prevalence of gout in Taiwan, the management of the disease remains poor. We found that only around one-third of prevalent gout cases involved patients who had contact with the health service in relation to their gout, and only one-fourth were actually prescribed ULT. We noticed no significant change in ULT prescription patterns during the study period, despite the publication of Taiwanese guidelines for the management of gout and hyperuricaemia in 2007 [40]. The poor management of gout seems to be a common problem globally [3,8,30,41-47]. Taking the United Kingdom as an example, the overall use of ULT in primary care has not changed in the past two decades, with only onefourth to one-third of people with gout being given ULT $[8,30]$. Other deviations from recommended standards of care have also been reported in the United Kingdom $[41,42,48]$. These lines of evidence underscore the lack of knowledge and interest in gout among primary care physicians, which in turn reflects a number of varied barriers to optimal care of patients with gout [3,49-51]. However, in a recent proof-of-principle study conducted in the United Kingdom, researchers found that all patients with gout were willing to take long-term ULT once they were given full information on gout and its treatment [52]. In addition, these well-informed patients exhibited excellent adherence, and nine of ten patients achieved the therapeutic target at 1 year. Therefore, the essential part of optimising care of patients with gout is likely to be physician education to improve knowledge and promote interest in gout.

There are several limitations of the present study. Firstly, we based our case definition on physicianrecorded diagnosis rather than according to American College of Rheumatology criteria [53], Rome [54] classification criteria or urate crystal identification. Secondly, we report 10-year period prevalence rather than lifetime prevalence, which theoretically would be higher. This is because of the inability to identify clinically silent patients who had no outpatient record of gout over the 10-year period. It is difficult to determine how many patients with gout were not included, because data on the length of asymptomatic intercritical gout periods are sparse. On the basis of estimates of the length of these intercritical gout periods in the case series reported by Yu et al. [21], an underestimation of $7 \%$ is probable. In addition to underestimation of prevalence, incidence would also be overestimated, as some incident gout cases could have included gout attacks prior to the 10 -year observation period. We reported geographic variations of gout prevalence and incidence and attribute the significantly higher prevalence and incidence in the eastern coastal areas and offshore islets to aggregation of aboriginals; however, we do not have ethnicity data to support this notion. Certainly, variation in distribution of gout risk factors may also result in regional variation of gout prevalence and incidence. This hypothesis requires further study to be confirmed. 


\section{Conclusions}

In this population-based study, we found a high prevalence and incidence of gout in Taiwan, and the regional differences of gout prevalence and incidence were large. Uricosuric agents are more commonly prescribed than xanthine oxidase inhibitors. During the study period, the prevalence of gout was stable, whereas the incidence decreased, in Taiwan. Despite the high prevalence and incidence of gout in Taiwan, the management of gout remains poor, with only one-fourth of patients receiving ULT, which can potentially cure gout.

\section{Additional files}

Additional file 1: Figure S1. Population pyramid of the general population in Taiwan in 2005. This figure describe the population structure in the general population in Taiwan in 2005

Additional file 2: Figure S2. Population pyramid of the general population in Taiwan in 2010. This figure describe the population structure in the general population in Taiwan in 2010

\section{Abbreviations}

APC: Annual percentage change; ARIC: Atherosclerosis Risk in Communities; Cl: Confidence interval; GPRD: General Practice Research Database; NHI: National Health Insurance; NHIRD: National Health Insurance Research Database; ULT: Urate-lowering treatment.

\section{Competing interests}

The authors declare that they have no competing interests.

\section{Authors' contributions}

CK, WZ and MD developed the study concept and designed the study. CK, $L S, K Y$ and $S L$ acquired the funding and data from the NHIRD. CK, MG, LS, WZ and MD analysed and interprets the data. CK, MG, LS, WZ and CK conducted statistical analysis. CK and WZ drafted the manuscript. WZ, MD and MG supervised the study. All authors participated in the critical revision of the manuscript for important intellectual content. All authors read and approved the final manuscript.

\section{Authors' information}

WZ and MD are joint senior authors.

\section{Acknowledgements}

We thank the National Science Council of Taiwan (project NSC 103-2314-B182A-070-MY2) and Chang Gung Memorial Hospital (project CMRPG3A0623) for financial support and the University of Nottingham for methodological assistance and infrastructure. The sponsors of the study had no role in its design and conduct; the collection, management, analysis and interpretation of the data; or the preparation, review or approval of the manuscript for publication. This study is based on the National Health Insurance Research Database, which is provided by the Bureau of National Health Insurance, Department of Health, and managed by the National Health Research Institutes, Taiwan. The interpretation and conclusions reported herein do not represent positions of the National Health Insurance Administration or the National Health Research Institute.

\section{Author details}

${ }^{1}$ Division of Rheumatology, Orthopaedics and Dermatology, School of Medicine, University of Nottingham, Academic Rheumatology, Clinical Sciences Building, Nottingham City Hospital, Hucknall Road, Nottingham NG5 1PB, UK. ${ }^{2}$ Division of Rheumatology, Allergy and Immunology, Chang Gung Memorial Hospital, 5, Fuxing street, Taoyuan 333, Taiwan. ${ }^{3}$ Division of Epidemiology and Public Health, School of Medicine, University of Nottingham, Clinical Sciences Building, Nottingham City Hospital, Hucknall Road, Nottingham NG5 1PB, UK. ${ }^{4}$ Department of Public Health, College of Medicine, Chang Gung University, 259, Wenhua 1st road, Taoyuan 333, Taiwan. ${ }^{5}$ Biostatistics Core Laboratory, Molecular
Medicine Research Centre, Chang Gung University, 259, Wenhua 1st road, Taoyuan 333, Taiwan.

Received: 3 July 2014 Accepted: 8 January 2015

Published online: 23 January 2015

\section{References}

1. Smith E, Hoy D, Cross M, Merriman TR, Vos T, Buchbinder R, et al. The global burden of gout: estimates from the Global Burden of Disease 2010 study. Ann Rheum Dis. 2014;73:1470-6. doi:10.1136/annrheumdis-2013-204647.

2. Wortmann RL, Schumacher HR, Becker MA, Ryan LM, editors. Crystal-induced arthropathies: gout, pseudogout, and apatite-associated syndromes. New York: Taylor \& Francis; 2006

3. Doherty M, Jansen TL, Nuki G, Pascual E, Perez-Ruiz F, Punzi L, et al. Gout: why is this curable disease so seldom cured? Ann Rheum Dis. 2012;71:1765-70.

4. Kuo CF, Yu KH, See LC, Chou IJ, Tseng WY, Chang HC, et al. Elevated risk of mortality among gout patients: a comparison with the national population in Taiwan. Joint Bone Spine. 2011;78:577-80.

5. Kuo CF, See LC, Luo SF, Ko YS, Lin YS, Hwang JS, et al. Gout: an independent risk factor for all-cause and cardiovascular mortality. Rheumatology (Oxford). 2010:49:141-6.

6. Choi HK, Curhan G. Independent impact of gout on mortality and risk for coronary heart disease. Circulation. 2007;116:894-900

7. Roddy E, Zhang W, Doherty M. The changing epidemiology of gout. Nat Clin Pract Rheumatol. 2007;3:443-9.

8. Kuo CF, Grainge MJ, Mallen C, Zhang W, Doherty M. Rising burden of gout in the UK but continuing suboptimal management: a nationwide population study. Ann Rheum Dis. 2014. doi:10.1136/annrheumdis-2013-204463.

9. Zhu Y, Pandya BJ, Choi HK. Prevalence of gout and hyperuricemia in the US general population: the National Health and Nutrition Examination Survey 2007-2008. Arthritis Rheum. 2011;63:3136-41.

10. Chou CT, Pei L, Chang DM, Lee CF, Schumacher HR, Liang MH. Prevalence of rheumatic diseases in Taiwan: a population study of urban, suburban, rural differences. J Rheumatol. 1994;21:302-6.

11. Chang SJ, Ko YC, Wang TN, Chang FT, Cinkotai FF, Chen CJ. High prevalence of gout and related risk factors in Taiwan's Aborigines. J Rheumatol. 1997:24:1364-9.

12. Chou CT, Lai JS. The epidemiology of hyperuricaemia and gout in Taiwan aborigines. Br J Rheumatol. 1998;37:258-62.

13. Lin KC, Lin HY, Chou P. Community based epidemiological study on hyperuricemia and gout in Kin-Hu, Kinmen. J Rheumatol. 2000;27:1045-50.

14. Chang HY, Pan WH, Yeh WT, Tsai KS. Hyperuricemia and gout in Taiwan: results from the Nutritional and Health Survey in Taiwan (1993-96). J Rheumatol. 2001:28:1640-6.

15. Lai SW, Liu CS, Lin T, Lin CC, Lai HC, Liao KF. Prevalence of gout and hyperuricemia in Taiwan: a hospital-based, cross-sectional study. South Med J. 2009;102:772-3.

16. Kuo CF, Yu KH, Luo SF, Chiu CT, Ko YS, Hwang JS, et al. Gout and risk of non-alcoholic fatty liver disease. Scand J Rheumatol. 2010;39:466-71.

17. Chuang SY, Lee SC, Hsieh YT, Pan WH. Trends in hyperuricemia and gout prevalence: Nutrition and Health Survey in Taiwan from 1993-1996 to 2005-2008. Asia Pac J Clin Nutr. 2011;20:301-8.

18. Kuo CF, Grainge MJ, See LC, Yu KH, Luo SF, Valdes AM, et al. Familial aggregation of gout and relative genetic and environmental contributions: a nationwide population study in Taiwan. Ann Rheum Dis. 2015;74:369-74. doi:10.1136/annrheumdis-2013-204067.

19. Friedlaender JS, Friedlaender FR, Reed FA, Kidd KK, Kidd JR, Chambers GK, et al. The genetic structure of Pacific Islanders. PLoS Genet. 2008;4:e19.

20. Klemp P, Stansfield SA, Castle B, Robertson MC. Gout is on the increase in New Zealand. Ann Rheum Dis. 1997;56:22-6.

21. Yu TF, Gutman AB. Efficacy of colchicine prophylaxis in gout: prevention of recurrent gouty arthritis over a mean period of five years in 208 gouty subjects. Ann Intern Med. 1961;55:179-92.

22. Kim HJ, Fay MP, Feuer EJ, Midthune DN. Permutation tests for joinpoint regression with applications to cancer rates. Stat Med. 2000;19:335-51.

23. McAdams MA, Maynard JW, Baer AN, Kottgen A, Clipp S, Coresh J, et al. Reliability and sensitivity of the self-report of physician-diagnosed gout in the campaign against cancer and heart disease and the atherosclerosis risk in the community cohorts. J Rheumatol. 2011;38:135-41.

24. Picavet HS, Hazes JM. Prevalence of self reported musculoskeletal diseases is high. Ann Rheum Dis. 2003;62:644-50 
25. O'Sullivan JB. Gout in a New England town: a prevalence study in Sudbury, Massachusetts. Ann Rheum Dis. 1972;31:166-9.

26. Arromdee E, Michet CJ, Crowson CS, O'Fallon WM, Gabriel SE. Epidemiology of gout: is the incidence rising? J Rheumatol. 2002;29:2403-6.

27. Usbott RD, Brand FN, Kannel WB, Castelli WP. Gout and coronary heart disease: the Framingham Study. J Clin Epidemiol. 1988:41:237-42.

28. Hochberg MC, Thomas J, Thomas DJ, Mead L, Levine DM, Klag MJ. Racial differences in the incidence of gout. The role of hypertension. Arthritis Rheum. 1995;38:628-32.

29. Stewart OJ, Silman AJ. Review of UK data on the rheumatic diseases-4. Gout. Br J Rheumatol. 1990;29:485-8.

30. Mikuls TR, Farrar JT, Bilker WB, Fernandes S, Schumacher Jr HR, Saag KG. Gout epidemiology: results from the UK General Practice Research Database, 1990-1999. Ann Rheum Dis. 2005;64:267-72.

31. Maynard JW, McAdams-Demarco MA, Law A, Kao L, Gelber AC, Coresh J, et al. Racial differences in gout incidence in a population-based cohort: atherosclerosis risk in communities study. Am J Epidemiol. 2014;179:576-83.

32. Yu KH, Luo SF. Younger age of onset of gout in Taiwan. Rheumatology (Oxford). 2003:42:166-70

33. Hall AP, Barry PE, Dawber TR, McNamara PM. Epidemiology of gout and hyperuricemia: a long-term population study. Am J Med. 1967;42:27-37.

34. Nishioka N, Mikanagi K. Clinical features of 4,000 gouty subjects in Japan. Adv Exp Med Biol. 1980;122A:47-54

35. Li R, Sun J, Ren LM, Wang HY, Liu WH, Zhang XW, et al. Epidemiology of eight common rheumatic diseases in China: a large-scale cross-sectional survey in Beijing. Rheumatology (Oxford). 2012;51:721-9.

36. Hosoya T, Ohno I, Ichida K, Peters GJ. Gout and hyperuricemia in Japan: perspectives for international research on purines and pyrimidines in man. Nucleosides Nucleotides Nucleic Acids. 2011;30:1001-10.

37. Ko YC, Wang TN, Tsai LY, Chang FT, Chang SJ. High prevalence of hyperuricemia in adolescent Taiwan aborigines. J Rheumatol. 2002;29:837-42.

38. Freeman J, Hutchison GB. Prevalence, incidence and duration. Am J Epidemiol. 1980;112:707-23.

39. Alho JM. On prevalence, incidence, and duration in general stable populations. Biometrics. 1992;48:587-92.

40. Tsay GJ, Yu KH, Liang TH, Tsai W-C, Wei CC, Hsieh TY. Taiwan guideline for the management of gout and hyperuricaemia. Taipei: Taiwan Rheumatology Association; 2007. http://imohw.tmu.edu.tw/idohtmu/wp-content/uploads/ 2013/04/04\%E5\%8F\%B0\%E7\%81\%A3\%E7\%97\%9B\%E9\%A2\%A8\%E8\%88\% 87\%E9\%AB\%98\%E5\%B0\%BF\%E9\%85\%B8\%E8\%A1\%80\%E7\%97\%87\%E8\%A8\% BA\%E7\%99\%82\%E6\%8C\%87\%E5\%BC\%95.pdf. Accessed 10 Feb 2015.

41. Mikuls TR, Farrar JT, Bilker WB, Fernandes S, Saag KG. Suboptimal physician adherence to quality indicators for the management of gout and asymptomatic hyperuricaemia: results from the UK General Practice Research Database (GPRD). Rheumatology (Oxford). 2005;44:1038-42.

42. Roddy E, Mallen CD, Hider SL, Jordan KP. Prescription and comorbidity screening following consultation for acute gout in primary care. Rheumatology (Oxford). 2010;49:105-11.

43. Neogi T, Hunter DJ, Chaisson CE, Allensworth-Davies D, Zhang Y. Frequency and predictors of inappropriate management of recurrent gout attacks in a longitudinal study. J Rheumatol. 2006:33:104-9.

44. Barber C, Thompson K, Hanly JG. Impact of a rheumatology consultation service on the diagnostic accuracy and management of gout in hospitalized patients. J Rheumatol. 2009;36:1699-704.

45. Sarawate CA, Brewer KK, Yang W, Patel PA, Schumacher HR, Saag KG, et al. Gout medication treatment patterns and adherence to standards of care from a managed care perspective. Mayo Clin Proc. 2006;81:925-34.

46. Reaves $E$, Arroll B. Management of gout in a South Auckland genera practice. J Prim Health Care. 2014;6:73-8.

47. Dalbeth N, House ME, Horne A, Petrie KJ, McQueen FM, Taylor WJ Prescription and dosing of urate-lowering therapy, rather than patient behaviours, are the key modifiable factors associated with targeting serum urate in gout. BMC Musculoskelet Disord. 2012;13:174.

48. Roddy $\mathrm{E}$, Zhang W, Doherty M. Concordance of the management of chronic gout in a UK primary-care population with the EULAR gout recommendations. Ann Rheum Dis. 2007:66:1311-5.

49. Spencer K, Carr A, Doherty M. Patient and provider barriers to effective management of gout in general practice: a qualitative study. Ann Rheum Dis. 2012;71:1490-5.

50. Reach $\mathrm{G}$. Treatment adherence in patients with gout. Joint Bone Spine. 2011;78:456-9.
51. Solomon DH, Avorn J, Levin R, Brookhart MA. Uric acid lowering therapy: prescribing patterns in a large cohort of older adults. Ann Rheum Dis. 2008;67:609-13.

52. Rees F, Jenkins W, Doherty M. Patients with gout adhere to curative treatment if informed appropriately: proof-of-concept observational study. Ann Rheum Dis. 2013;72:826-30.

53. Wallace SL, Robinson H, Masi AT, Decker JL, McCarty DJ, Yu TF. Preliminary criteria for the classification of the acute arthritis of primary gout. Arthritis Rheum. 1977;20:895-900

54. Kellgren JH, Jeffrey MR, Ball J, editors. The epidemiology of chronic rheumatism. Oxford: Blackwell; 1963.

\section{Submit your next manuscript to BioMed Central and take full advantage of:}

- Convenient online submission

- Thorough peer review

- No space constraints or color figure charges

- Immediate publication on acceptance

- Inclusion in PubMed, CAS, Scopus and Google Scholar

- Research which is freely available for redistribution

Submit your manuscript at www.biomedcentral.com/submit
C) Biomed Central 